\title{
Homossexualidade, homofobia e a agressividade do palavrão. Seu uso na educação sexual escolar
}

\section{Homosexuality, homophobia and the aggressiveness of curse words. Its use in the school sexual education}

\author{
Amadeu Roselli-Cruz ${ }^{1}$
}

\begin{abstract}
RESUMO
O uso do palavrão pode gerar violência e até crime de morte na escola. Muitos professores e famílias relatam a dificuldade em lidar com ele. 90\% da agressividade do palavrão se referem à sexualidade do ofendido e/ou de sua família, em especial à mãe, e à homossexualidade. Muitos dos livros de educação sexual sequer fazem referência à homossexualidade e, em nenhum deles encontramos conteúdos sobre o palavrão. O discurso religioso mais contribui para aumentar as possibilidades de punição do que à compreensão e aceitação do sujeito com esses comportamentos. Nossa pesquisa estudou jovens do sexo masculino entre 9 e 14 anos de escola pública de periferia, com o objetivo de verificar o uso do palavrão, a ofensa e a conotação expressa e entendida, mais especificamente referente a mecanismos de homofobia entre adolescentes na escola. A despreocupação para com o palavrão contribui para a homofobia e agressividade dentro da escola.

Palavras-chave: homofobia; homossexualidade; palavrão; educação sexual; projeto psicopedagógico.
\end{abstract}

1 Psicólogo, jornalista e biomédico. Doutor em Linguística. Programa de Pós-graduação em Neurociência e Comportamento do Instituto de Ciências Biológicas da Universidade Federal de Minas Gerais (ICB-UFMG), Brasil. 


\begin{abstract}
The use of swear words may generate violence and even murder at school. Many teachers and families report having difficulty in dealing with it. $90 \%$ of the swear word aggressiveness refers to the offended person's and/or to hers or his family's sexuality, especially to the mother, and to homosexuality. Many of the sex education books do not even refer to homosexuality and, in none of them were found contents related to swear words. The religious discourse contributes to increase the possibilities of punishment rather than to understand and accept the individual who is the offended one. Our research has studied young state school boys in the outskirts between the age of 9 and 14, aiming to check the usage of swear words, the offense itself, the expressed and understood connotation, more specifically relative to homophobia mechanisms among teenagers at school. The unconcern in relation to the use of swear words contributes to homophobia and aggressiveness at school.

Keywords: homophobia; homosexuality; swear word; sex education; psycho-pedagogical project.
\end{abstract}

\title{
Introdução
}

Aranha (2002) discorre sobre o uso da palavra como arma em nossa sociedade. $\mathrm{O}$ insulto pouco conhecido é duplamente contundente, pois, além de desqualificar o adversário, ainda o faz passar por ignorante. Além de xingado, ele sente-se diminuído por não saber o significado daquela palavra que lhe foi dirigida. Nesse sentido, o palavrão cumpre a função de ofender, tanto pelo seu significado, como pelo tom de voz do ofensor ao proferi-lo, como, por vezes, pela ignorância de sua representação. Estudos no campo das violências, envolvendo preconceito, discriminação e o fenômeno do bullying, apontam o xingamento (uso de palavrão), difamação e calúnia como práticas comuns nas relações interpessoais na escola e nos ambientes virtuais de acesso preferencial entre estudantes (cyberbullying).

Provocar a reflexão sobre o uso do palavrão, a ofensa, a conotação expressa e entendida, mais especificamente referente a mecanismos de homofobia entre adolescentes na escola é o objetivo desse artigo, contribuindo para a construção de metodologias de abordagem da temática no âmbito da educação sexual para uma escola sem homofobia.

Num primeiro momento, o jovem não sabe os significados dos palavrões 
que lhe foram dirigidos, mas percebe o tom de ameaça, e, com o tempo, deslinda os seus códigos linguísticos. E pode, ou não, passar a usá-los também. Isso vai depender de sua educação familiar, escolar, religiosa e convivência em ambientes sociais propícios ou não à sua pronúncia. "O uso de expressões como aidético, homossexualismo ${ }^{2}$, opção sexual, o travesti, sapatão, veado, gilete, além de errado, pode ser ilegal e/ou prejudicar a honra e dignidade de milhões de pessoas e seus familiares" (ABGLT, 2010, p. 7).

Para Houaiss (2001) palavrão é uma palavra grosseira e/ou obscena. Obsceno é aquilo que no domínio da sexualidade, fere o pudor. É aquilo que não está de acordo com o pudor. Seus sinônimos, em geral são impropério, baixo calão e palavra feia. $\mathrm{O}$ dito palavrão tem caráter ofensivo, embora nem toda palavra ofensiva possa ser chamada de palavrão. Este, em geral, guarda alguma relação muito próxima com a sexualidade de quem é ofendido.

Em qualquer dicionário, de qualquer língua, encontramos verbetes que podem ser classificados como palavrões. Em língua portuguesa em uma consulta dirigida aos dicionários lideres de mercado, e com maior número de páginas, caso do Houaiss (2001) e do Ferreira (1999), encontramos centenas de ditos palavrões. Isso levou a que o mercado editorial visse nisso um mercado promissor. E passou a editar dicionários de palavrões. O de Souto Maior (2010) já está em sua quarta edição revista e ampliada, e com prefácio do antropólogo Gilberto Freyre. Mattoso (1990) escreveu um dicionário do palavrão inglês-português e português-inglês. Catalogamos uma dezena de dicionários do palavrão feitos por gráficas editoras sem presença significativa no mercado de livros. Ou seja, o palavrão é também uma questão comercial.

O seu estudo deve ser interdisciplinar, abrangendo a linguística, educação, letras, sociologia, antropologia, biologia, entre outras áreas do conhecimento e, claro, o estudo da sexualidade humana. A religião também se interessa pelos palavrões, porém, num contexto muito particular. A sua proibição pura e simples e a imposição de penas exaustivas como fazer repetição de dezenas de orações para expiação da culpa. Ou ainda a condenação ao inferno quando morrer. Inúmeras crianças nos relataram essas experiências danosas ao seu desenvolvimento. A repressão sexual passa historicamente pela religião até os tempos atuais (CHAUÍ, 1994).

A imprensa tem destacado o aumento da violência na escola e seu entorno. A crônica policial tem apresentado crimes de morte na escola que se iniciou

2 O sufixo "ismo" refere-se a doença. Em 1973, o "homossexualismo" foi retirado da lista dos distúrbios mentais da American Psychology Association, dos Estados Unidos, passando a ser utilizado o termo homossexualidade. No Brasil, em 1999, o Conselho Federal de Psicologia, com a Resolução 001/99, considera que a "homossexualidade não constitui doença, nem distúrbio e nem perversão" (ABGLT, 2010, p. 11). 
com um palavrão evoluindo para a agressão física e para a morte. Professores e pais de alunos também vêm de forma crescente relatando aumento na violência entre seus alunos e filhos. E todos pedem providencias de alguém.

Existe uma aceitação para com o uso do palavrão dependendo das condições de uso e, sobretudo de quem o pronuncia. Em 11/08/2010 durante o Programa do Jô, na Rede Globo de Televisão, foi feita uma homenagem a vários comediantes. O Jô Soares enunciou cerca de duas dezenas de palavrões, junto com seus convidados, com conotações sexuais e foi aplaudido, como sempre. Esse artista e muitos outros, como o Costinha ${ }^{3}$, já representaram personagens homossexuais de forma caricata e estereotipada. Os personagens eram irreais e nada contribuíam para a educação da diversidade sexual. O palavrão com cunho homossexual e o palavrão teatral são frequentes no Brasil e tem impacto na escola.

Em função desse teatro com estereótipos homossexuais e com o significado sexual de alguns palavrões, alguns alunos podem sofrer um tipo de bullying com o xingamento e com a representação de seus atos motores, gestos e fala estereotipada, que caracteriza um tipo de bullying homofóbico. E a escola não está preparada para isso.

\section{Preconceito, estereótipos, bullying e o uso de palavrões}

Para que a escola desenvolva ações efetivas para a prevenção do uso de palavrão como forma de comunicação interpessoal, evitando evoluir para formas mais violentas, precisa tomar consciência da força do preconceito, dos estereótipos e da discriminação nas relações sociais. Para Ferreira (1995) o preconceito é "o conceito ou opinião formados antecipadamente, sem maior ponderação ou conhecimento dos fatos"e lembra que o preconceito gera suspeita, intolerância, ódio irracional ou aversão (crenças, credos, ideologias, pessoas, etc.). Para Carolina Bori, em palestra proferida no Curso Escola de professores na luta contra o preconceito racial (NUPES - USP, 2004), o preconceito é um “evento privado, ligado à dimensão psicológica da pessoa. Ele é aprendido junto com outras pessoas, no convívio social; se acumula em todos os contatos sociais desde a primeira infância".

Para Magalhães (1960), o estereótipo pode ser entendido como "uma representação coletiva, consistente em verdadeiro esquema, verbalizado ou não", onde "as características de indivíduos, grupos ou instituições são simplificadas e reduzidas a uma imagem cuja evocação pode provocar as mais diversas des-

3 Humorista (já falecido) que se destacou pelo frequente uso de palavrão e suas apresentações artísticas. 
cargas emocionais". Normalmente presente nas brincadeiras estudantis, de forma quase espontânea surgem nos apelidos e nas provocações, muitas vezes atingindo níveis de perversidade, fortalecidos pelas palavras e gestos, difíceis de tornarem-se suportáveis, principalmente quando expressos onde há plateia. Nesse sentido, alguns estudantes conseguem transformar em palavrões (ce-dêefe, puxa-saco) comportamentos e características que deveriam ser estimuladas.

No contexto escolar favorável aos preconceitos e aos estereótipos, onde a educação sexual não se faz presente ou reforça cenários de intolerância, com base em fundamentalismos de toda ordem, o palavrão pode referendar o bullying escolar que "abrange todos os atos de violência (física ou não) que ocorrem de forma intencional e repetitiva contra um ou mais alunos, impossibilitados de fazer frente às agressões sofridas" (SILVA, 2010, p.13). A autora destaca a versatilidade das atitudes maldosas e as mais variadas formas de se expressar. Sobre as palavras e palavrões é possível identificar, relacionado à homossexualidade ou não, servem para "insultar, ofender, xingar, fazer gozações, colocar apelidos pejorativos, fazer piadas ofensivas, zoar, assediar, insinuar" (SILVA, 2010, p. 23). Nesse sentido, as palavras e palavrões encontram, no campo virtual, graças aos avanços tecnológicos, uma forma contundente de agredir, caluniar e espalhar maledicências.

Se por um lado, para a juventude torna-se fácil expressar oralmente ou utilizar os recursos da escola (incluindo os banheiros), do celular ou internet para dar sentido aos palavrões, este passa a ser um primeiro problema desta pesquisa sobre as relações entre a homossexualidade e o palavrão: a escolha das palavras que usaríamos para descrever o fenômeno. A sociedade erudita e científica exige um tipo de linguagem - mais educada - que foge ao escopo desta pesquisa. Por isso esta justificativa. Em pesquisa pode-se fazer tudo o que se quer desde que se possa explicar. Por isso esta explicação, que será detalhada na metodologia.

\section{Metodologia}

Para escrevermos os palavrões usamos os critérios da imprensa leiga, que, quando necessário, faz uso deles diretamente sob certas condições estipuladas em normas editoriais. O jornal Folha de São Paulo recomenda evitar o uso de palavrões, mas, se necessário, pedir autorização prévia para a Diretoria de Redação (MANUAL DA REDAÇÃO, 2010, p. 93). Assim, consultamos os organizadores deste dossiê e fomos informados de que se o palavrão estiver contextualizado, não haverá problemas com o seu uso. 
Assim, faremos o uso estritamente necessário e sempre que possível, após o primeiro uso, trocaremos por abreviaturas ou formas mais brandas, trocando por termos mais anatomo-fisiológicos e eufemísticos. Estes cuidados apenas revelam o quanto que questões sexuais, sobretudo na educação familiar e escolar, ainda são polêmicos e delicados

A pesquisa é um estudo descritivo de observação participante com características etnográficas, como descritas por Angrosino (2009, p. 16). O método lida com pessoas no sentido coletivo do termo e não com indivíduos. Estuda pessoas com algum grau de convivência por algum interesse e objetivo, como alunos de uma escola, detendo-se em aspectos que podem fazer parte de uma cultura, como é o caso da sexualidade. Para o autor, a etnografia é a ciência de descrever um grupo humano, suas instituições, seus comportamentos interpessoais, suas produções materiais e suas crenças.

Os pesquisadores fazem parte da escola e assim, estão autorizados pela comunidade escolar a conviver e participar dos seus problemas e da busca de soluções. Até porque podem também fazer parte dos problemas. Mesmo assim, os responsáveis pelos participantes assinaram o termo de esclarecimento livre e esclarecido.

O grupo pesquisado foi de 52 alunos do sexo masculino com idades entre 9 e 14 anos completos, matriculados já no mínimo dois anos naquela escola pública. Determinamos o mínimo de dois anos, pois um mínimo de convivência entre os alunos era necessário para os objetivos da pesquisa. Aplicamos questionários e fizemos entrevistas aos alunos que se interessaram pela pesquisa. Entre três e cinco encontros com grupos de até 8 alunos foram feitos discutindo os resultados das entrevistas individuais e questionários.

O objetivo inicial da pesquisa era saber por que, e como, o palavrão ofende tanto um jovem uma vez que faz parte de sua cultura de comunicação. Depois, passamos a estudar a correlação entre palavrão e sexualidade. Em seguida, estudamos as relações entre o palavrão e a homossexualidade.

\section{Histórico}

Em nossa linha de pesquisa em Psicologia Escolar com ênfase em prevenção do abuso de drogas e sexualidade o palavrão era acessório aos grandes temas em estudo até o episódio envolvendo uma bolsista de iniciação científica. Ela, bióloga, 35 anos, casada, mãe de três filhas adolescentes, teve áspera discussão com um aluno de 14 anos que não fez um trabalho escolar dentro das normas 
concordadas pela turma, na última aula do turno da manhã numa sexta-feira.

$\mathrm{O}$ aluno, agressivo, não concordando em refazer o trabalho, disse para a professora: "vá tomar na sua buceta" (vagina). A professora, de perfil calmo, sempre muito afetiva, respondeu: "Sim, vou. Mas hoje não, pois é sexta-feira e estou muito cansada. Mas neste final de semana vou fazer muito isso. Gosto e meu marido também. E não precisamos da sua recomendação. E você, vai fazer o que? Quer falar mais sobre isso?"

Foi um silencio total, relata a professora. A turma de alunos recriminou o colega, defendendo a professora. Logo bateu o sinal terminando a aula, os alunos saíram, a professora caiu em si, arrependeu-se pelo que disse e começou a chorar. Comunicou o acontecido para a direção da escola que não se interessou pelo acontecido. Na semana seguinte, trouxe o caso para a reunião do grupo de pesquisa.

O caso foi estudado e decidimos ouvir mais aos alunos e contextualizar a questão sexual, o palavrão, a anatomia e a fisiologia sexual, além dos aspectos linguísticos envolvidos. $\mathrm{O}$ trabalho foi proposto aos alunos, e a seus pais, que tiveram ótima recepção à proposta. Logo de início, o aluno pivô da pesquisa se antecipou e pediu desculpas para a professora. Isso facilitou o clima para o trabalho que se desenvolveu por quatro meses.

Com cerca de um mês de trabalho, outros alunos de outras turmas se interessaram e passaram a também participar das atividades de discussão sobre sexo e convivência humana, nome este dado pelo próprio grupo de alunos. A direção da escola foi participada da atividade, mas nunca se manifestou sobre ela. Os pais foram comunicados da proposta e a julgaram interessante e pertinente aos seus filhos.

\section{Resultados e Discussão}

O trabalho se iniciou discutindo as formas de insulto entre as pessoas, trabalhando as relações interpessoais entre alunos e entre estes e funcionários e professores. O palavrão foi escolhido a forma verbal mais ofensiva. Pedimos que cada aluno listasse os 10 palavrões que julgasse mais ofensivo. Em seguida deveriam dizer se o palavrão anotado tem ou não conotação sexual. Depois, os palavrões sexuais teriam de ser classificados segundo critérios eleitos pelo grupo. Um primeiro critério escolhido foi classificar em heterossexual e homossexual. Outro critério foi a da intensidade da ofensa do palavrão, muito ou pouco ofensivo. 
Entre os 520 palavrões anotados, 85\% (442) têm conotação sexual. E 15\% (78) não têm conotação sexual. Cada palavrão foi discutido pelo professor em seu contexto histórico, anatômico e da fisiologia sexual. Um aluno pesquisou na internet e descobriu o significado histórico da palavra "caralho". Essa palavra é muito frequente entre os termos ofensivos, mas nenhum aluno sabia explicar o sentido exato da ofensa e a estrutura frasal de que participa o termo.

Para Houaiss (2001) caralho é sinônimo de pênis e pode ter o sentido de interjeição significando admiração e/ou indignação (caralho, que maravilha esta paisagem) (não admito esta atitude, caralho). $\mathrm{O}$ uso deste palavrão como interjeição é mais frequente em Portugal do que no Brasil. Porém, o histórico da palavra ajuda a explicar sua semântica sexual. Caralho é o nome que se dava nos antigos barcos a vela da época do descobrimento do Brasil àquele cesto (ou gávea), também chamado de vigia, colocado no alto de mastro principal da caravela, onde ficava o vigia, marinheiro que observava o horizonte para avistar terra, recifes, barcos inimigos e cardumes para a pesca, tendo uma visão privilegiada, pela altura em que ficava.

Embora a vista fosse ótima, o lugar era péssimo. O barco a vela balança muito e seu deslocamento lateral e vertical é muito maior lá em cima, e estimulava em demasia o labirinto e o órgão vestibular do marinheiro lá colocado, levando-o a vomitar, ter tonturas e diarreias. Por isso, o marinheiro indicado para ficar no caralho era o rebelde, agressivo, que para lá subia como punição. Assim se dizia que quem subia para o caralho voltava todo "cagado e vomitado." E só podia se lavar depois de horas, ao descer de lá. Assim, "ir para o caralho" era muito ofensivo.

Com o passar dos anos o termo foi ganhando outras conotações e significados. Caralho já significava pênis. Assim, "ir para a casa do caralho" passou a significar que apenas quem tivesse pênis - órgão masculino - tinha coragem para ir para o caralho. Porque ele tinha um. É preciso ter coragem, coisa que é atribuída mais ao homem do que para a mulher. Os significados tornaram-se polissêmicos.

Se ficarmos no literal, com o significado de pênis, então "a casa do caralho" é a vagina, que o recebe durante um ato sexual. Com muita razão, nesse sentido, alguns movimentos homossexuais norte-americanos insistem que o ânus também é a "casa do caralho." Ou seja, a expressão "vá para a casa do caralho" tem um duplo sentido. Pode, por um lado, significar: "vou fazer você sofrer." E também pode significar: "entre numa vagina." Ou "entre num ânus." Neste último sentido, em nossa cultura machista, não é assim muito ofensivo quando se refere à vagina. A frequência de uso deste palavrão caiu exponencialmente entre os alunos da pesquisa, após os debates.

Em seguida pedimos que nos dissessem por que os demais palavrões 
ofendiam na visão deles. Ouvimos uma resposta já esperada e outra que foi uma surpresa. Já sabíamos que grande número de palavrões ofende por referirse à sexualidade de pessoas de nossa família a quem dedicamos muito carinho, afeição e amor. Somos educados para isso pela sociedade. Sobretudo aquelas do sexo feminino como mãe, irmã, namorada e esposa.

Na progressão de agressividade do palavrão, o "filho da puta" (FDP) ocupa o primeiro lugar. Afinal ele se refere à vida sexual da mãe do ofendido. E mais ainda, ao exercício que essa mãe faz de uma profissão ligada a uma atividade sexual pública. Crimes são cometidos por ofensas desse tipo, mais do que qualquer outro palavrão.

Nas discussões com os alunos ficou claro que fazer referência à vida sexual promiscua de um familiar - sobretudo do sexo feminino - alcança um alto grau de ofensa e que não pode ficar sem resposta. Mesmo um ofendido franzino, atacado por um grandalhão peso pesado, tem de reagir para "não perder a moral". "A sua e a da familiar ofendida." Mesmo sabendo que poderá apanhar fisicamente. Apanho, mas defendo minha mãe, dizem eles para a maioria dos casos que envolvem mãe. A mãe revelou-se um alvo prioritário para ofensas que não podem ficar sem resposta. Por isso, os palavrões que a envolvem trazem mais violência física do que os demais.

\section{Palavrões e homossexualidade}

A resposta surpresa foi o alto grau de correlação entre o palavrão xingado e a interpretação de que ele está se referindo à própria sexualidade do ofendido. A ofensa do palavrão que se refere à sexualidade do ofendido pode ser classificada em quatro grupos: 1 . O ofendido não faz sexo porque não consegue fazer (tem dificuldade erétil); 2 . Não gosta de sexo e não o faz; 3 . Ninguém quer fazer sexo com o ofendido; 4 . O ofendido é homossexual.

Neste último grupo de palavrões, o maior fator de ofensa foi conferido pelos alunos ao clássico "vai tomar no cú". Para eles se alguém faz isso só pode ser um homossexual. Se alguém é xingado assim e ainda de "viado", é necessária uma resposta imediata para negar essa designação. Se não negar, confirma o xingamento. E a negação pode ser feita com uma troca de xingamentos e/ou com agressão física.

Esse palavrão tem outra forma que é menos frequente, mas é considerada mais ofensiva: "vou comer o seu cú". A agressão foi personalizada com a identificação do agente, o sujeito da frase. A frase agressiva indicia o agente ativo e o 
passivo do processo. Ela pode ser apresentada de forma mais resumida, embora não muito menos agressiva, na forma: "vou te comer".

Câmara Cascudo, em seu museu em Natal-RN e Gilberto Freyre, em Recife-PE, têm anotações sobre a sexualidade que envolve a frase acima, que pode ser dita como: "vou comer você, sexualmente falando". No século 19 e até o meio do século 20, parceiros sexuais não casados, oficialmente, tinham muita dificuldade em encontrar um lugar para fazer sexo escondido. Não havia a liberalidade dos atuais motéis, que floresceram apenas na década de 1970. Os hotéis regulares exigiam a certidão de casamento para aceitar a reserva de um casal. Para casais homossexuais era mais fácil, pois homem com homem, e mulher com mulher, podiam hospedar-se sem apresentar certidão de casamento. E a homossexualidade era manifesta de forma mais sutil e discreta.

O encontro sexual atípico dependia de condições como saírem todos da residência, do escritório, entrar escondido em automóveis e parar em lugares ermos, pois ainda não havia os atuais drive-in. Mas ter automóvel era muito difícil e caro, pois eram importados e não havia financiamento.

Como na época não havia edifícios arranha-céus, a densidade demográfica era muito baixa e as casas residenciais tinham terrenos enormes, aproveitados com a plantação de pomares, hortas e jardins. Coisas que desapareceram com a urbanização acelerada e exploração imobiliária. E esse espaço periférico às casas era aproveitado para o sexo, sobretudo no pomar, onde havia sombra, folhas espalhadas como um tapete macio, ambiente perfumado e com temperatura mais agradável.

Era conveniente deixar alguém de confiança montando guarda para evitar ser surpreendido durante o ato íntimo. E, para preservar as identidades e o segredo do ato, não se dizia o que se faria no pomar, e muito menos com quem. O código era dizer: "vou comer uma fruta ou "vou chupar uma fruta". É uma razão óbvia para se estar num pomar. E faz sentido linguístico e antropológico.

Comer ou chupar uma fruta depende de uma concordância. Dizemos vou chupar uma manga, vou chupar uma uva. Vou comer o abacaxi, vou comer pêssegos. Tente trocar os verbos e as frutas. Ficará estranho para a língua portuguesa dizer vou comer uvas. Vou chupar abacaxis. A partir daí houve uma adaptação para a sexualidade.

Assim, podemos dizer, vou "chupar os seios dela," "vou chupar a vagina, os pés, o pescoço." E dizemos "vou comer a bunda, a vagina." Na escala de agressividade do palavrão incorre em alto índice a expressão: "vou comer a bunda do seu pai". A acusação do palavrão, sexualmente postada, é a de que o pai do ofendido é homossexual. E o jovem filho dele se vê na obrigação de defender a família.

Chamar alguém, pelo palavrão, de homossexual, pode levar o jovem ofen- 
dido - que não é homossexual - a criar resistência e rejeição à homossexualidade. Afinal, estou sendo ofendido assim porque eles existem. Se eles não existissem eu não seria ofendido. Esta conclusão ficou muito clara durante as discussões, quando analisadas sob a visão da semiolinguística e da teoria da argumentação como descrita por Perelman e Olbrechts-Tyteca (1966).

Se a defesa for feita com xingamentos trocados, ganhará aquele que atribuir ao outro o maior número de ofensas em grau mais expressivo e em maior quantidade. Quem souber menos palavrões perde o jogo. A escola simplesmente apartar essa discussão e/ou interromper a briga, apenas vai adiar o processo ainda sem vencedor. E a resolução poderá se ocorrer fora da escola, com consequências mais graves.

Durante a pesquisa bibliográfica para este trabalho procuramos saber se os livros de educação sexual do acervo das cinco maiores universidades com campus na cidade de Belo Horizonte abordavam a homossexualidade e o palavrão. Apenas $50 \%$ dos livros abordam a homossexualidade. E nenhum livro tratava do assunto palavrão. Considerando que o palavrão trata da sexualidade e que sexualidade envolve a homossexualidade, é incompreensível que a educação sexual na escola não trate disso.

\section{Conclusão}

O palavrão, e seu polissêmico significado, é uma ótima atividade a ser contemplada no projeto psicopedagógico das escolas do ensino fundamental e médio. O seu estudo cabe dentro das diretrizes dos PCNs - Parâmetros Curriculares Nacionais em estudos sociais, biologia, línguas e história, por exemplo.

As escolas mais sensíveis e atentas às mudanças globais de nosso tempo já estão procurando iniciar processos de inovação e de reforma que poderão dar conta dos novos desafios. É necessário modificar não somente a organização escolar, os conteúdos programáticos, os métodos de ensino e estudo, mas, sobretudo, a mentalidade da educação formal. (SILVA, 2010, p. 63).

Trabalhar o palavrão na escola pode ser uma estratégia para o ensino da educação sexual, diminuição da agressividade e da homofobia. Os professores, 
de maneira geral, ainda não estão preparados para esse trabalho. Cabe à escola preocupar-se com a questão com treinamentos e muita discussão com os pais dos alunos. A curiosidade não satisfeita sobre sexualidade e a preocupação com a possibilidade de ser ofendido - pelo palavrão - com a acusação de ser homossexual, pode levar ao baixo desempenho escolar. O palavrão acusativo de homossexualidade, bem como de diferentes identidades de gênero, já levou alunos a pedir transferência de escola, com transtornos para a família.

Palavrões dirigidos ao filho já fizeram pais tomarem atitudes agressivas contra colegas do filho e seus respectivos pais. E isto também pode ser responsável pela evasão escolar. Um simples palavrão que insinue orientação sexual diferente do modelo heteronormativo pode implicar em medos, resposta agressiva com aumento da violência, além de baixo desempenho, reprovação e evasão da escola.

Os autores de livros de educação sexual, que existem em grande quantidade no Brasil, devem dedicar-se mais ao tema da diversidade sexual, orientação sexual e identidade de gênero. E também dedicar-se ao estudo e orientação sobre o uso do palavrão na escola. Os movimentos sociais de LGBTT - lésbicas, gays, bissexuais, travestis e transgêneros vêm trabalhando as questões da diversidade sexual em várias frentes e conseguido sucesso inclusive em questões legislativas. Em seus manifestos e publicações de qualidade, falta a abordagem do palavrão.

Entre as inúmeras funções da educação de nossas crianças e adolescentes está ensinar o respeito pelas diferenças. Educar para o convívio harmonioso entre as diversidades é obrigação de todas as instituições de ensino. O despreparo e o preconceito dos adultos no ambiente escolar e/ou familiar tendem a perpetuar e agravar o problema, além de contribuir para a ocorrência de suas cruéis e indesejáveis consequências. É fundamental que nossos jovens aprendam e compreendam que a homofobia, bem como qualquer outro tipo de discriminação, é, sobretudo, um desrespeito à liberdade e à individualidade de cada ser humano. (SILVA, 2010, p.149).

Os saberes já produzidos neste campo do conhecimento devem ser compartilhados e democraticamente disseminados na escola, família e comunidade. Não há mais espaço para a ignorância sexual, homofobia e não reconhecimento da diversidade sexual e cultural. 


\section{REFERÊNCIAS}

ABGLT. Manual de comunicação LGBT: lésbicas, gays, bissexuais, travestis e transexuais. Curitiba: Ajir Artes Gráficas e Editora, 2010.

ANGROSINO, Michael. Etnografia e observação participante. Porto Alegre: Artmed. 2009.

ARANHA, Altair J. Dicionário brasileiro de insultos. Cotia: Atêlier Editorial, 2002.

BORI, Carolina. Palestra proferida no Curso Escola de professores na luta contra o preconceito racial. NUPES - USP. São Paulo, 2004.

CHAUÍ, Marilena. Repressão sexual: essa nossa (des)conhecida. São Paulo: Circulo do Livro, 1994.

FERREIRA, Aurélio Buarque de Holanda. Novo dicionário da língua portuguesa. São Paulo: Nova Fronteira, 1995.

. Novo Aurélio. O dicionário da língua portuguesa. Rio de Janeiro: Nova Fronteira, 1999.

HOUAISS, Antonio. Dicionário da língua portuguesa. São Paulo: Objetiva, 2001.

MAGAlHÃES, Álvaro (Org.). Dicionário enciclopédico ilustrado. Porto Alegre: Globo, 1960.

MANUAL DA REDAÇÃO. Folha de São Paulo. São Paulo: Publifolha, 2010.

MATTOSO, Glauco. Dicionarinho do palavrão e correlatos. Rio de Janeiro: Record, 1990.

PERELMAN, Chaïn; OLBRECHTS-TYTECA, Lucie. Tratado da argumentação: a nova retórica. São Paulo: Martins Fontes, 1996.

SILVA, Ana Beatriz Barbosa. Bullying: mentes perigosas nas escolas. Rio de Janeiro: Objetiva, 2010.

SOUTO MAIOR, Mário. Dicionário do palavrão. 4 ed. São Paulo: Leitura, 2010.

Texto recebido em junho de 2010.

Texto aprovado em outubro de 2010. 